\title{
Soccer Training: An Effective Exercise Mode to Prevent and Treat Childhood Obesity?
}

\author{
Liquan Cao ${ }^{1}$, Zhen Guo ${ }^{1}$, Sijie $\operatorname{Tan}^{1}$ and Jianxiong Wang*2 \\ ${ }^{1}$ Tianjin Physical Fitness Research Center, Department of Health and Exercise Science, China \\ ${ }^{2}$ School of Health and Wellbeing, Faculty of Health, Engineering, and Sciences, Australia
}

*Corresponding author: Jianxiong Wang, School of Health and Wellbeing, Faculty of Health, Engineering, and Sciences, Australia

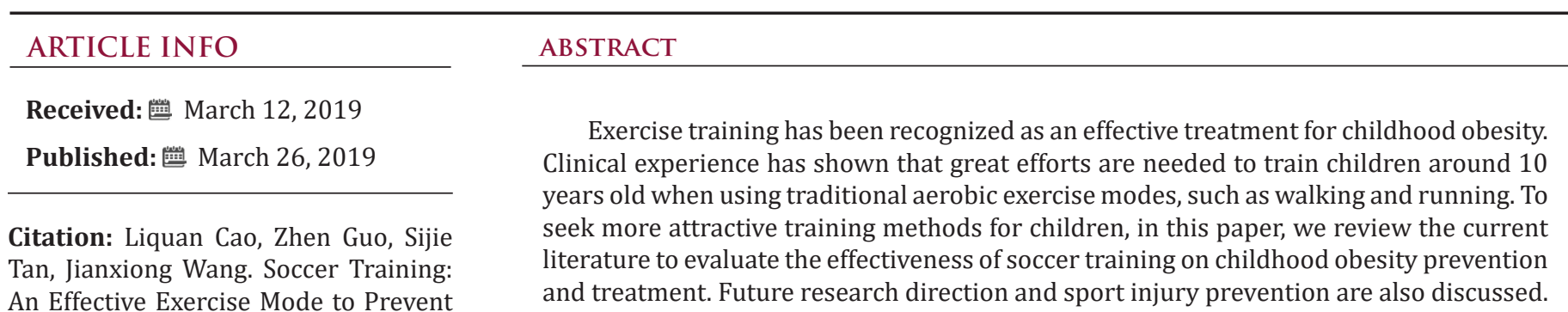

An Effective Exercise Mode to Preven and Treat Childhood Obesity?. Biomed J Sci \& Tech Res 16(3)-2019. BJSTR. MS.ID.002844.

\section{Introduction}

Obesity is affecting many children worldwide and leading to the development of various pediatric diseases [1]. Childhood obesity will be carried into adulthood if not properly treated early [2]. To achieve healthy growth, the first choice for childhood obesity prevention and treatment is the engagement in physical activity to improve body composition, cardiovascular function, and musculoskeletal function. Aerobic exercise training is the most commonly used method. Based on the clinical experience from our research team, one of the major difficulties in exercise training study with obese children is that enormous efforts were demanded when the training program employed walking and running as the main exercise modes [3-5]. The researchers might spend a lot of time encouraging, motivating, and organizing the children when they lost interest and felt bored during the exercise. This situation has persuaded us to seek more attractive and interesting physical activities in exercise training studies with children. In the literature, there are some studies about improving children's health through various ball games. However, the purpose of this paper was to focus on whether soccer training would be suitable for childhood obesity prevention and treatment.

\section{Effects of Soccer Training on Children's Health}

The game of soccer has various physical activities which can be utilized during exercise training to maintain the interest and motivation of the children. Employed soccer skills training, our team has reported that the 10 -week training program significantly decreased body fat mass, body fat $\%$, and abdominal fat mass; while improved running performance, muscle strength and endurance, and cardiovascular function in 9- to 10-year-old boys with normal body mass, compared with the non-exercise control group [6]. Evidence from the studies with overweight or obese boys also indicated that soccer training can improve body composition, muscular and cardiovascular fitness variables of the participants. One study reported that after 12 weeks of soccer training, overweight or obese boys aged 11-13 years decreased their body fat mass by $8 \%$, increased muscular fitness (measured by jump performance) by $17 \%$, and aerobic capacity (estimated through the Yo-Yo test) by $80 \%$ [7]. Another study showed that a 6-month soccer program decreased body fat mass and waist circumference; increased bone mineral density; decreased total cholesterol, lowdensity lipoprotein cholesterol, and leptin; increased high-density 
lipoprotein cholesterol and adiponectin; and increased maximal oxygen uptake in 10-year-old obese boys [8]. In summary, these studies have provided valuable information on the effectiveness of soccer training on childhood obesity prevention and treatment. An interesting research direction in future studies may recruit more girls with overweight or obesity as the participants and investigate the effects of soccer training in girls.

\section{Injury Prevention}

The issue of sport injuries must be carefully considered by researchers when conducting soccer training in children. Soccer training may cause sport injury, but the one-season risks in young children aged 5 to 14 years was reported at 1.05\% [9]. Furthermore, the potential risks can be reduced through proper warm-up activity at the beginning of the training sessions [10].

\section{Acknowledgement}

This study was supported by Tianjin 2017 Social Science Project Funds (TJTYQN17-002). The authors declare that there are no conflicts of interest.

\section{References}

1. Speiser PW, Rudolf MC, Anhalt H, Camacho Hubner C, Chiarelli F, et al. (2005) Consensus statement: childhood obesity. J Clin Endocrinol Metab 90(3): 1871-1887.

2. Herman KM, Craig CL, Gauvin L, Katzmarzyk PT (2009) Tracking of obesity and physical activity from childhood to adulthood: The Physical Activity Longitudinal Study. Int J Pediatr Obes 4(4): 281-288.

\section{ISSN: 2574-1241}

\section{DOI: 10.26717/BJSTR.2019.16.002844}

Jianxiong Wang. Biomed J Sci \& Tech Res

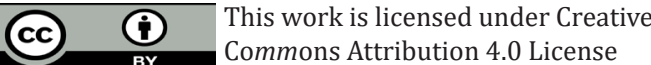

Submission Link: https://biomedres.us/submit-manuscript.php
3. Tan S, Yang C, Wang J (2010) Physical training of 9 to 10-year-old children with obesity to lactate threshold intensity. Pediatr Exerc Sci 22(3): 477-485.

4. Tan S, Wang J, Cao L (2016) Exercise training at the intensity of maximal fat oxidation in obese boys. Appl Physiol Nutr Metab 41(1): 49-54.

5. Tan S, Chen C, Sui M, Xue L, Wang J (2017) Exercise training improved body composition, cardiovascular function, and physical fitness of 5 -year-old children with obesity or normal body mass. Pediatr Exerc Sci 29(2): 245-253.

6. Wang J, Cao L, Xie P, Wang J (2018) Recreational football training improved health-related physical fitness in 9- to 10-year-old boys. J Sports Med Phys Fitness 58(3): 326-331.

7. Cvetković N, Stojanović E, Stojiljković N, Nikolić D, Scanlan AT, et al. (2018) Exercise training in overweight and obese children: Recreational football and high-intensity interval training provide similar benefits to physical fitness. Scand J Med Sci Sports 28(Suppl 1): 18-32.

8. Seabra A, Katzmarzyk P, Carvalho MJ, Seabra A, Coelho E Silva M, et al. (2016) Effects of 6-month soccer and traditional physical activity programmes on body composition, cardiometabolic risk factors, inflammatory, oxidative stress markers and cardiorespiratory fitness in obese boys. J Sports Sci 34(19): 1822-1829.

9. Morris K, Simon JE, Grooms DR, Starkey C, Dompier TP, et al. (2017) The epidemiology of overuse conditions in youth football and high school football players. J Athl Train 52(10): 976-981.

10. Gatterer H, Lorenzi D, Ruedl G, Burtscher M (2018) The "FIFA 11t" injury prevention program improves body stability in child (10 year old) soccer players. Biol Sport 35(2): 153-158.

\begin{tabular}{ll}
\hline REMEARCHES & Assets of Publishing with us \\
\hline - Global archiving of articles
\end{tabular}

